\title{
The Investigation on Color Purity of Blue Organic Light-Emitting Diodes (BOLED) by Hole-Blocking Layer
}

\author{
Kan-Lin Chen, ${ }^{1}$ Chien-Jung Huang, ${ }^{2}$ Wen-Ray Chen, ${ }^{3}$ Chih-Chieh Kang, \\ Wen-How Lan, ${ }^{5}$ and Yu-Chen Lee ${ }^{2}$ \\ ${ }^{1}$ Department of Electronic Engineering, Fortune Institute of Technology, Kaohsiung 83160, Taiwan \\ ${ }^{2}$ Department of Applied Physics, National University of Kaohsiung, Kaohsiung 81148, Taiwan \\ ${ }^{3}$ Department of Electronic Engineering, National Formosa University, Huwei, Yunlin 63201, Taiwan \\ ${ }^{4}$ Department of Electro-Optical Engineering, Southern Taiwan University of Science and Technology, Tainan 71005, Taiwan \\ ${ }^{5}$ Department of Electrical Engineering, National University of Kaohsiung, Kaohsiung 81148, Taiwan
}

Correspondence should be addressed to Kan-Lin Chen; klchen@fotech.edu.tw and Chien-Jung Huang; chien@nuk.edu.tw

Received 18 October 2013; Accepted 31 October 2013

Academic Editor: Teen-Hang Meen

Copyright (C) 2013 Kan-Lin Chen et al. This is an open access article distributed under the Creative Commons Attribution License, which permits unrestricted use, distribution, and reproduction in any medium, provided the original work is properly cited.

Organic light-emitting diodes (OLEDs) with triple hole-blocking layer (THBL) structure, which consist of 2,9-dimethyl-4,7diphenyl-1,10-phenanthroline (BCP), 4,4'-bis(2,2' diphenyl vinil)-1,1'-biphenyl (DPVBi), and $\left(4,4^{\prime}\right.$-N, $\mathrm{N}^{\prime}$-dicarbazole)biphenyl (CBP), have been fabricated. Regardless of applied voltage variation, the luminous efficiency of the OLEDs with THBL structure was increased by $41 \%$ as compared with the dual hole-blocking layer (DHBL) structure. The CIE coordinates of $(0.157,0.111)$ of device with THBL structure are close to pure blue emission than that of other devices of DHBL. There is a coordinate with the slight shift of $\pm \Delta_{x, y}=(0.001,0.008)$ for the device with THBL structure during the applied voltage of 6-9 V. The results indicate that the excitons can be effectively confined in the emitting layer of device, leading to an enhancement of luminance efficiency and more stable coordinate.

\section{Introduction}

Recently, organic light-emitting diodes (OLEDs) have attracted much attention due to their superior characteristics such as high luminance, wide range of colors, and wide viewing angles. OLEDs have been regarded as the next generation display technology. Many approaches have been tried to realize full-color displays [1], and it requires three basic emitting colors, red, green, and blue. However, the blue OLEDs still have inherent problems of low efficiency, poor color purity, and short lifetime in comparison with other red or green OLEDs [2]. It is important to keep the color stability with applied voltage in the blue OLEDs. So far, there is still a distance to achieve standard Commission International de L'Eclairage (CIE) coordinates $(0.14,0.08)$ of blue OLEDs. Generally, there are many structures of emitting layer to obtain blue OLEDs, such as single emitting layer, double emitting layer, blue guest doped layer, or multiple-quantumwell (MQW) layer [3-12]. Shi et al. utilized MQW structure of [4,4-bis[N-(1-naphthyl)-N-phenylamino]biphenyl (NPB)/ 2,9-dimethyl-4,7-diphenyl-1,10-phenanthroline (BCP) $]_{n}$ that makes hole-electron balance in emitting layer, resulting in the CIE coordinates of $(0.1747,0.1059)$ [11]. Bang et al. used $4,4^{\prime}$-bis (2,2' diphenyl vinil)-1, $1^{\prime}$-biphenyl (DPVBi) and tris-8hydroxy-quinoline aluminum $\left(\mathrm{Alq}_{3}\right)$ as double emitting layer, leading to CIE coordinates of $(0.150,0.137)$ at $11 \mathrm{~V}$ [2]. However, the CIE coordinates are not stable by using the above structure or method, resulting from the shift of the excitons recombination zone.

In this study, we improved the color purity of OLEDs by using structure of triple-hole blocking layer (THBL), which consisted of alternate $\left(4,4^{\prime}-\mathrm{N}, \mathrm{N}^{\prime}\right.$-dicarbazole) biphenyl (CBP) and BCP. Both of them have excellent electron mobility and holes barrier ability. The CBP layer compared with BCP layer has better electron mobility and is $3 \times 10^{-4} \mathrm{~cm}^{2} /$ $\mathrm{V}^{-1} \mathrm{~s}^{-1}$, which will favor electron injection from BPhen layer to emitting layer [13]. The BCP layer can effectively control the carrier in the emitting layer that will enable an increase 
<smiles>c1ccc(N(c2ccc(-c3ccc(N(c4ccccc4)c4cccc5ccccc45)cc3)cc2)c2cccc3ccccc23)cc1</smiles>

(a)<smiles>Cc1cc(-c2ccccc2)c2ccc3c(-c4ccccc4)cc(C)nc3c2n1</smiles>

(b)<smiles>C(=C(c1ccccc1)c1ccccc1)c1ccc(-c2ccc(C=C(c3ccccc3)c3ccccc3)cc2)cc1</smiles>

(c)

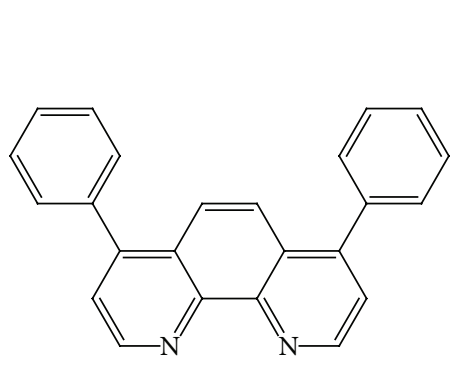

(d)<smiles>CN1C=CC=C2C=CCC(O[Si](C)(OC3C=CC=CC3)OC3CC=CC4=C3N3C=CC=CC4=CC=C3)N21</smiles>

(e)

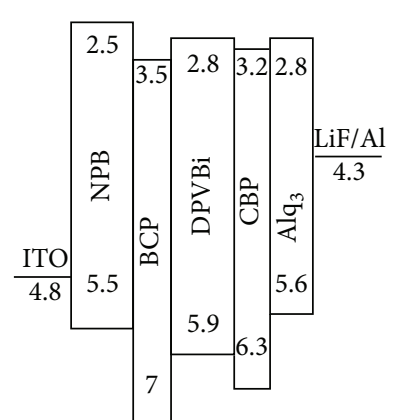

(f)

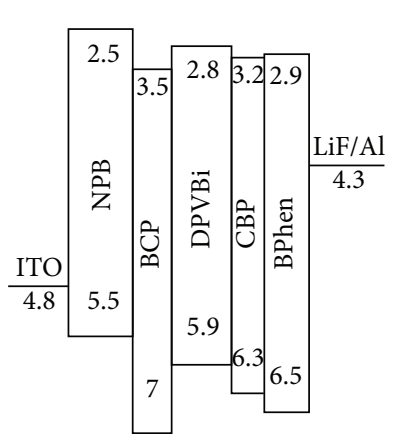

(g)

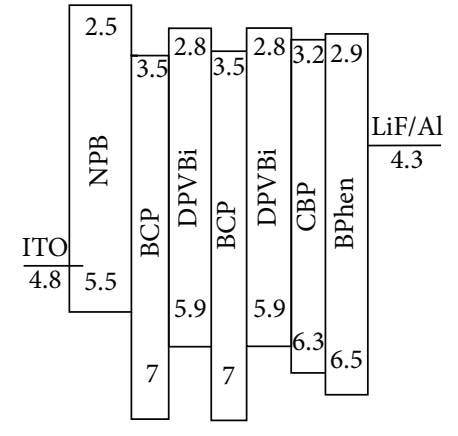

(h)

Figure 1: The chemical structures of (a) NPB, (b) BCP, (c) DPVBi, (d) BPhen, and (e) $\mathrm{Alq}_{3}$ and the schematic energy band diagrams of (f) device A, (g) device B, and (h) device C.

in the recombination of emission region. It is due to the fact that there is a higher occupied molecular orbital (HOMO) of $7.0 \mathrm{eV}$ for BCP. However, we used the THBL structure so that the carrier can be effectively confined and controlled in the DPVBi emitting layer, resulting in the fact that the CIE color coordinates of devices can be considerably improved. Simultaneously, the mechanism of the color stability of device with various structures is presented.

\section{Experimental}

Indium tin oxide (ITO) coated glass with a sheet resistance of approximately $15 \Omega / \square$ was consecutively cleaned in ultrasonic bath containing detergent water, acetone, ethanol, and deionized (DI) water for 20 min each and then dried with a nitrogen $\left(\mathrm{N}_{2}\right)$ flow. The chemical structures of organic materials used and the schematic energy band diagrams of the devices A-C in this study are shown in Figure 1. These structures were as follows:

(A) ITO/NPB (40 nm)/BCP (8 nm)/DPVBi (40 nm)/CBP $(2 \mathrm{~nm}) / \mathrm{Alq}_{3}(20 \mathrm{~nm}) / \mathrm{LiF}(0.5 \mathrm{~nm}) / \mathrm{Al}(100 \mathrm{~nm}) ;$

(B) ITO/NPB (40 nm)/BCP (8 nm)/DPVBi $(40 \mathrm{~nm}) / \mathrm{CBP}$ $(2 \mathrm{~nm}) / \mathrm{BPhen}(10 \mathrm{~nm}) / \mathrm{LiF}(0.5 \mathrm{~nm}) / \mathrm{Al}(100 \mathrm{~nm})$;

(C) ITO/NPB $(40 \mathrm{~nm}) / \mathrm{BCP}(\mathrm{I})(6 \mathrm{~nm}) / \mathrm{DPVBi}(20 \mathrm{~nm}) /$ BCP (II) $(2 \mathrm{~nm}) / \mathrm{DPVBi}(20 \mathrm{~nm}) / \mathrm{CBP}(2 \mathrm{~nm}) / \mathrm{BPhen}$ $(10 \mathrm{~nm}) / \mathrm{LiF}(0.5 \mathrm{~nm}) / \mathrm{Al}(100 \mathrm{~nm})$. 


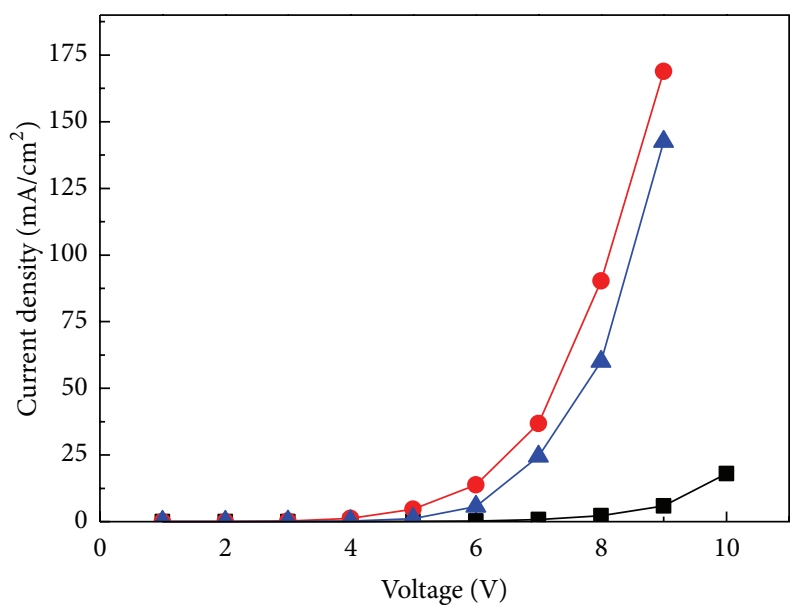

- Device A
$-\quad$ Device B
$-\quad$ Device C

(a)

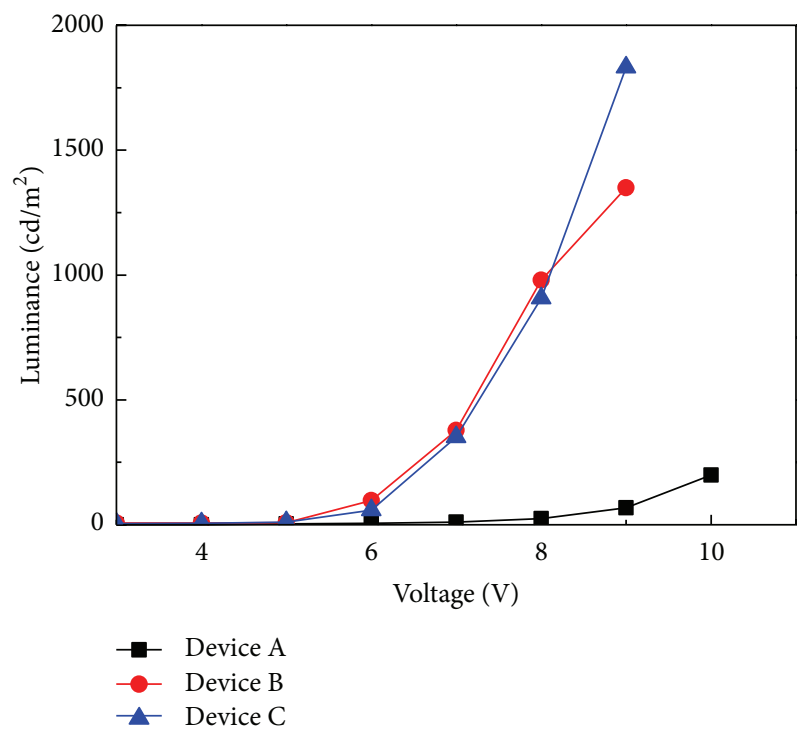

(b)

Figure 2: The (a) current density-voltage and (b) luminance-voltage characteristics of the devices A-C.

In the device, NPB is used as hole-injecting layer and hole-transport layer. The BCP and CBP are used as holeblocking layer inserted between DPVBi and HTL. The DPVBi acts as blue-emitting layer. The $\mathrm{Alq}_{3}$ and 4,7-diphenyl-1,10phenanthroline (BPhen) are used as a HTL. LiF and Al are used as an electron-injection layer and cathode, respectively. All of the deposition procedures involved thermal evaporation in a vacuum chamber $\left(<10^{-6}\right.$ Torr $)$. The organic layers were sequentially evaporated onto the ITO coated-glass substrate. The deposition rates of all organic materials were monitored by an oscillating quartz thickness monitor (Sigma, SID-142). The deposition rates were about $0.2 \sim 0.5 \AA / \mathrm{s}$ for organic layers and $5 \AA / s$ for cathode $(\mathrm{Al})$ and $\mathrm{LiF}$. CIE coordinates, electroluminescence (EL) spectra, and luminance were measured by the photospectrometer (Kollmorgen
Instrument PR-655, USA) and the current-voltage characteristics were simultaneously measured by the programmable power source (Keithley SourceMeter 2400, USA), controlled using computer software (Chief I-V-L system, Taiwan). All measurements were carried out at room temperature under ambient.

\section{Results and Discussion}

Figures 2(a) and 2(b) show the current density-voltage and luminance-voltage characteristics of devices, respectively. Generally, the applied voltage is defined as turn-on voltage when the current density of device reaches the one-tenth of maximum value of the current density. In Figure 2(a), the turn-on voltages of device A-C are 9.5, 5.5, and $6.2 \mathrm{~V}$, respectively. The turn-on voltage of device $\mathrm{A}$ is higher than that of devices B-C. It is attributed to the different electron transport layers $\left(\mathrm{Alq}_{3}\right.$, BPhen) in the devices. It is well known that the electron mobility of BPhen $\left(2.4 \times 10^{-4} \mathrm{~cm}^{2} / \mathrm{V}^{-1} \mathrm{~s}^{-1}\right)$ is higher than that of $\mathrm{Alq}_{3}\left(4.7 \times 10^{-6} \mathrm{~cm}^{2} / \mathrm{V}^{-1} \mathrm{~s}^{-1}\right)[14,15]$. However, the ability of electron injection from cathode to the emitting layer can increase via using an electron transport layer with higher electron mobility, resulting in a decrease in the turn-on voltage of device. In addition, from the turn-on voltages of devices $\mathrm{B}$ and $\mathrm{C}$, there is a high turn-on voltage in device $\mathrm{C}$ due to inserting a thin $\mathrm{BCP}$ layer in the emitting layer to form the THBL structure.

By comparing devices $\mathrm{A}$ and $\mathrm{B}$, the luminance is greatly improved from $68 \mathrm{~cd} / \mathrm{m}^{2}$ to $1350 \mathrm{~cd} / \mathrm{m}^{2}$ at $9 \mathrm{~V}$. It can be ascribed to using the $\mathrm{BPhen}$ to replace the $\mathrm{Alq}_{3}$, resulting in the fact that more electrons inject from the cathode to the DPVBi and generate more excitons in the DPVBi layer.li The luminance of devices B and C are 1350 and $1831 \mathrm{~cd} / \mathrm{m}^{2}$ at $9 \mathrm{~V}$, respectively. The enhancement of the luminance in device $\mathrm{C}$ as compared with device $\mathrm{B}$ can be attributed to three factors: (1) THBL has better excitons confinement ability, (2) an increase in excitons formation in EML, and (3) there is formation both emitting layers (DPVBi) in THBL of device C.

In the devices, holes are accumulated and confined in the BCP layers because of the existence of the barrier at the interface of NPB/BCP. Hence, the hole mobility in the multilayer is expected to be decreased, and the performance of device $\mathrm{C}$ is expected to be enhanced. The luminous efficiency-current density characteristic is shown in Figure 3. The major parameters are summarized in Table 1 . The maximum luminous efficiencies of devices $\mathrm{B}$ and $\mathrm{C}$ are 1.08 and $1.52 \mathrm{~cd} / \mathrm{A}$, respectively. The luminous efficiency of device $\mathrm{C}$ is $41 \%$ higher than that of device B. It shows that there is a better carrier balance in device $\mathrm{C}$. The electrons are confined and accumulated in the lowest unoccupied molecular orbital (LUMO) level of DPVBi/BCP/DPVBi potential well in device $\mathrm{C}$ due to the existence of potential barrier at the DPVBi/BCP (II) and BCP (I)/DPVBi heterointerfaces. As a result, the balance of electron and hole can be improved by inserting a thin BCP layer in device $C$, forming the THBL structure, and thus more carriers will be confined within both the DPVBi layers. 


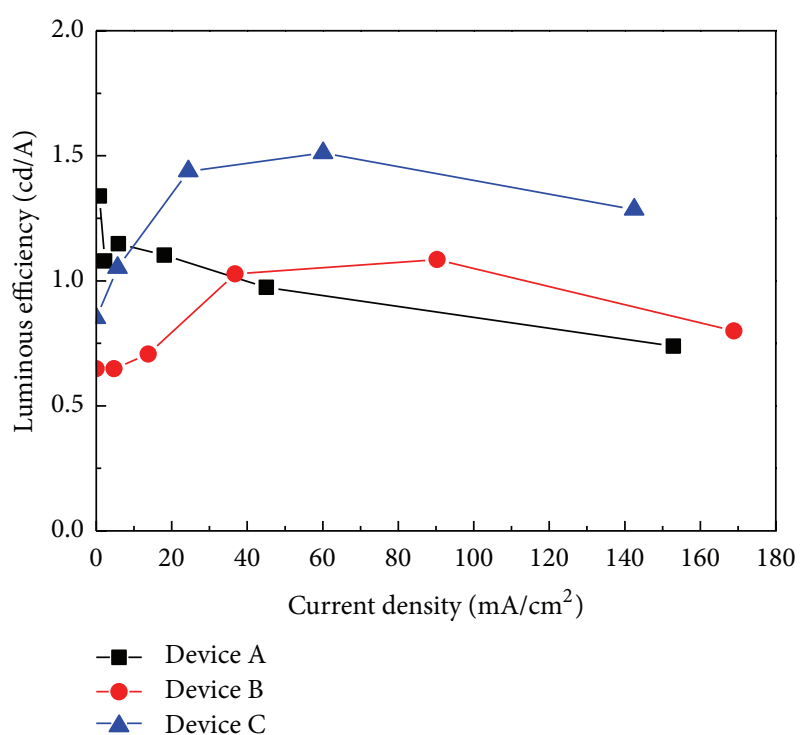

FIgURE 3: The luminance efficiency-current density characteristics of the devices A-C.

TABle 1: Performance of devices A-C.

\begin{tabular}{lccc}
\hline & Device A & Device B & Device C \\
\hline $\begin{array}{l}\text { Turn-on voltage }(\mathrm{V}) \\
\text { Luminance }\left(\mathrm{cd} / \mathrm{m}^{2}\right)\end{array}$ & 9.5 & 5.5 & 6.2 \\
$\begin{array}{l}\text { Luminance efficiency } \\
(\mathrm{cd} / \mathrm{A})\end{array}$ & 1.15 & 1350 & 1830 \\
$\begin{array}{l}\text { Wavelength peak } \\
(\mathrm{nm})\end{array}$ & 448 & 444 & 1.28 \\
$\begin{array}{l}\text { FWHM }(\mathrm{nm}) \\
\mathrm{CIE} \pm \Delta_{x, y}\end{array}$ & 68 & 65 & 436 \\
\hline
\end{tabular}

Figure 4 shows the normalized electroluminescent (EL) spectra of the devices A-C at the same current density of $10 \mathrm{~mA} / \mathrm{cm}^{2}$. The EL peaks of devices A-C are at 448,444 , and $436 \mathrm{~nm}$, respectively. The EL peaks of devices A and B are near to the PL peak of NPB $(446 \mathrm{~nm})$ [16]. It can be directly inferred and demonstrated that major holes were accumulated in the interface of the NPB/BCP and electronhole recombination occurred in NPB layer, resulting in the blue emission from the NPB layer. The EL peak of the device C is consistent with the PL peak of DPVBi (436 nm) [17]. It is due to the insertion of thin $\mathrm{BCP}$ layer in the middle of DPVBi layer, leading to the fact that the major holes were confined in the HOMO level of BCP (I)/DPVBi/BCP (II) potential well in device $C$ and recombined with electron in the DPVBi layer. From the energy level of Figure 1, the LUMO of BCP is $-3.5 \mathrm{eV}$ and is higher than that of DPVBi, so the inserted thin BCP (II) layer can confine the electron and prevent it from transporting from blue DPVBi layer to NPB layer. In Figure 4, the full width at half maximum (FWHM) of devices A-C are 68,65 , and $65 \mathrm{~nm}$, respectively. It can be seen in Figure 4 that there is a little color-mixing phenomenon of device $\mathrm{A}$ and it emits blue emission because the spectrum has a broad peak.

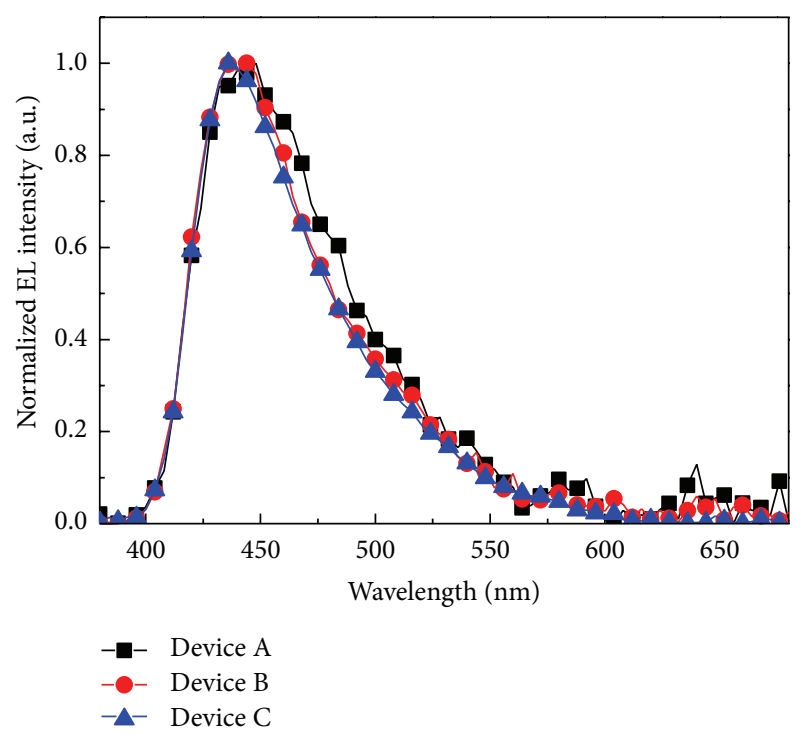

FIGURE 4: The normalized EL intensity spectra characteristics of the devices A-C at the current density of $10 \mathrm{~mA} / \mathrm{cm}^{2}$.

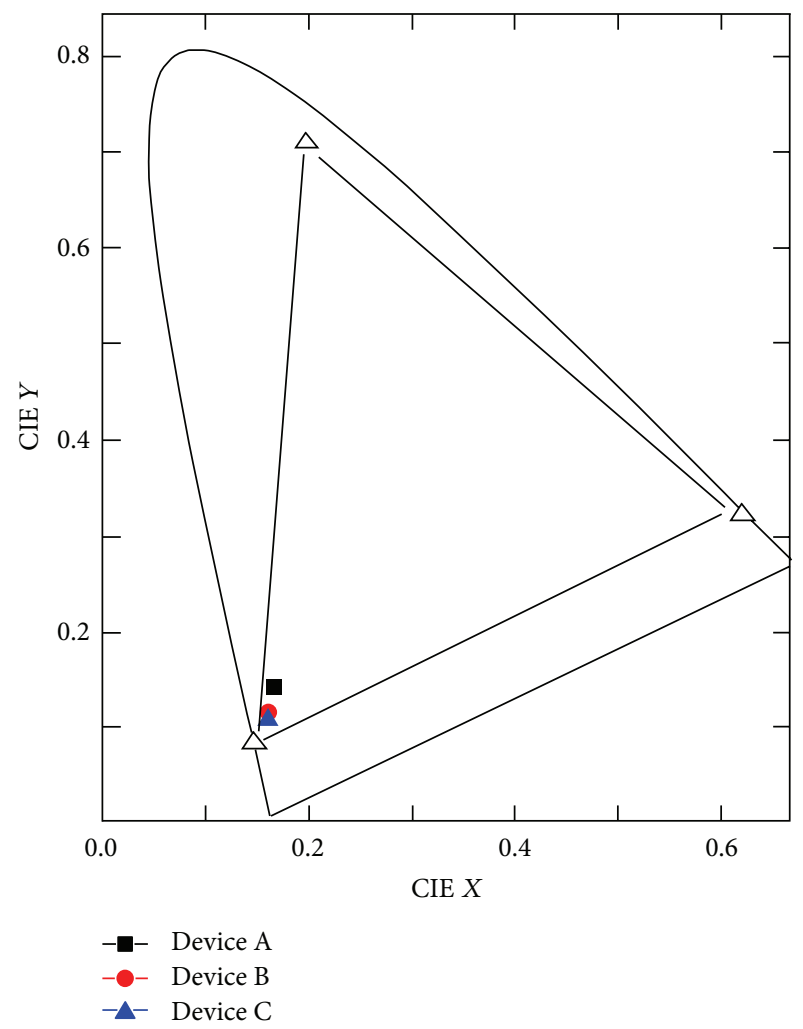

FIgUre 5: The CIE chromaticity coordinates of devices A-C at the applied voltage of $9 \mathrm{~V}$.

That is to say, the blue emission in device $\mathrm{C}$ is more pure than that of other devices.

Figure 5 shows the CIE coordinates of devices as a function of applied voltage. The CIE coordinates of device $\mathrm{A}$, device $\mathrm{B}$, and device $\mathrm{C}$ at $9 \mathrm{~V}$ are $(0.166,0.135),(0.157$, $0.113)$, and $(0.157,0.111)$, respectively. The CIE coordinates 
of device A are far away from the pure blue emission with CIE coordinates of $(0.14,0.08)$. It is attributed to the portion of carriers recombination at the $\mathrm{Alq}_{3}$ layer, generating slight green emission. The phenomenon is consistent with the result obtained in Figure 4. Besides, the CIE coordinates of device $\mathrm{A}$ are $(0.166,0.135)$ at $9 \mathrm{~V}$. The difference in CIE coordinates of device $\mathrm{A}$ is $\pm \Delta_{x, y}=(0.010,0.005)$. Thus, the function of BPhen to replace the $\mathrm{Alq}_{3}$ is not only due to its higher mobility but also due to its higher HOMO energy level which can avoid the hole to cross the CBP barrier layer, keeping off a mix of green light and far CIE coordinates of pure blue light. The CIE coordinates of devices B-C are $(0.157,0.113)$ and $(0.157,0.111)$ at $9 \mathrm{~V}$, respectively. By comparison with device A, the color coordinates of the devices $\mathrm{B}-\mathrm{C}$ are close to the pure blue region. The variation in CIE coordinates of devices $\mathrm{B}-\mathrm{C}$ is only $\pm \Delta_{x, y}=(0.000,0.004)$ and $(0.001,0.008)$, respectively. All the above results reveal that the displacement of the CIE coordinates for the device $\mathrm{C}$ at high voltage is obviously small in comparison with that of devices A-B, indicating that there is a better stability and more standard CIE coordinate of blue emission in device $\mathrm{C}$. This is because the emission region of the OLEDs with a THBL consisting of BCP layer and CBP layer is confined within both DPVBi layers. Hence, the performance of near blue emitting devices with a THBL structure of BCP and CBP is greatly improved which is attributed to the improved hole-electron balance and that can be further attributed to hole barrier in the HBL structure. So by adjusting the number of multiple HBL, the amount of hole injection into emitting layer can be controlled. In this study, THBL structure outperforms dual-HBL (DHBL) structure in both luminance and efficiency, enabling electrons to be injected into the device easily and increasing electronhole pair recombination in EML to achieve carrier effective balance.

\section{Conclusions}

In summary, the OLEDs with THBL and DHBL structure are fabricated and investigated. With THBL structure, it can efficiently control the holes transport and achieve an electronhole pair balance, the efficiency of which is improved by $41 \%$ as compared with the DHBL. The optimized blue CIE coordinates of $(0.157,0.111)$ at $9 \mathrm{~V}$ and coordinates shift only $\pm \Delta_{x, y}=(0.001,0.008)$ were obtained. These results indicate that the enhancement of luminance efficiency and the more stable purity of blue color can be achieved by using THBL due to excitons confined in the EML.

\section{Acknowledgment}

This work was partially supported by the National Science Council of the Republic of China under Contract no. NSC102-2221-E-390-019-MY2.

\section{References}

[1] H. Aziz, "Degradation mechanism of small molecule-based organic light-emitting devices," Science, vol. 283, no. 5409, pp. 1900-1902, 1999.
[2] H. S. Bang, D. U. Lee, T. W. Kim, S. M. Han, J. H. Seo, and Y. K. Kim, "Efficiency stabilization in deep-blue organic lightemitting devices with a double emitting layer acting as electron and hole trapping layers," Thin Solid Films, vol. 516, no. 16, pp. 5649-5653, 2008.

[3] C. J. Huang, C. C. Kang, T. C. Lee, W. R. Chen, and T. H. Meen, "Improving the color purity and efficiency of blue organic light-emitting diodes (BOLED) by adding hole-blocking layer," Journal of Luminescence, vol. 129, no. 11, pp. 1292-1297, 2009.

[4] C.-J. Huang, T.-H. Meen, K.-C. Liao, and Y.-K. Su, “The mechanism of efficiency enhancement with proper thickness of DPVBi layer for blue organic light-emitting devices (BOLED)," Journal of Physics and Chemistry of Solids, vol. 70, no. 3-4, pp. 765-768, 2009.

[5] D. U. Lee, D. C. Choo, T. W. Kim, J. H. Seo, J. H. Park, and Y. K. Kim, "Enhancement of efficiency in blue organic light-emitting devices with nanoscale barrier and trapping layers embedded in an emitting layer and a hole transport layer," Thin Solid Films, vol. 517, no. 17, pp. 5326-5329, 2009.

[6] W. Song, M. Meng, Y. H. Kim et al., "High efficient and color stable WOLED using double white emissive layer," Journal of Luminescence, vol. 132, no. 8, pp. 2122-2125, 2012.

[7] Khizar-ul-Haq, M. A. Khan, X. Y. Jiang et al., "Blue organic light-emitting diodes with low driving voltage and maximum enhanced power efficiency based on buffer layer $\mathrm{MoO}_{3}$," Journal of Luminescence, vol. 129, no. 10, pp. 1158-1162, 2009.

[8] H. S. Bang, S. Y. Seo, D. C. Choo et al., "Effect of doped emitting layer on electrical and optical properties in blue organic lightemitting devices," Thin Solid Films, vol. 517, no. 17, pp. 5314-5317, 2009.

[9] H.-P. Lin, F. Zhou, X.-W. Zhang et al., "Enhanced color stability and improved performance in white organic light-emitting devices by utilizing a double-graded structure," Synthetic Metals, vol. 161, no. 11-12, pp. 1133-1136, 2011.

[10] H. Zhu, Z. Xu, S. Zhao et al., "Study on the influences of quantum well structure on the performance of organic light emitting devices," Displays, vol. 32, no. 3, pp. 102-105, 2011.

[11] Y.-M. Shi, Z.-B. Deng, D.-H. Xu, and J. Xiao, "Organic lightemitting diodes with improved hole-electron balance and tunable light emission with aromatic diamine/bathocuproine multiple hole-trapping-layer," Displays, vol. 27, no. 4-5, pp. 166$169,2006$.

[12] Y. Qiu, Y. Gao, P. Wei, and L. Wang, "Organic light-emitting diodes with improved hole-electron balance by using copper phthalocyanine/aromatic diamine multiple quantum wells," Applied Physics Letters, vol. 80, no. 15, pp. 2628-2630, 2002.

[13] J.-W. Kang, S.-H. Lee, H.-D. Park et al., "Low roll-off of efficiency at high current density in phosphorescent organic light emitting diodes," Applied Physics Letters, vol. 90, no. 22, Article ID 223508, 2007.

[14] T. Yasuda, Y. Yamaguchi, D.-C. Zou, and T. Tsutsui, "Carrier mobilities in organic electron transport materials determined from space charge limited current," Japanese Journal of Applied Physics, vol. 41, no. 9, pp. 5626-5629, 2002.

[15] M. A. Khan, W. Xu, K.-U. Khizar-Ul-Haq et al., "Electron mobility of 4,7-diphyenyl-1,10-phenanthroline estimated by using space-charge-limited currents," Journal of Applied Physics, vol. 103, no. 1, Article ID 014509, 2008.

[16] H. Xu, Y. Yue, H. Wang, L. Chen, Y. Hao, and B. Xu, "Single-crystal structure, photophysical characteristics and 
electroluminescent properties of bis(2-(4-trifluoromethyl-2hydroxyphenyl) benzothiazolate)zinc," Journal of Luminescence, vol. 132, no. 4, pp. 919-923, 2012.

[17] M. Zhang, Z. Chen, L. Xiao, B. Qu, and Q. Gong, "Highcolor-quality blue top-emitting organic light-emitting diodes with enhanced contrast ratio," The Japanese Journal of Applied Physics, vol. 52, Article ID 05DC17, p. 4, 2013. 

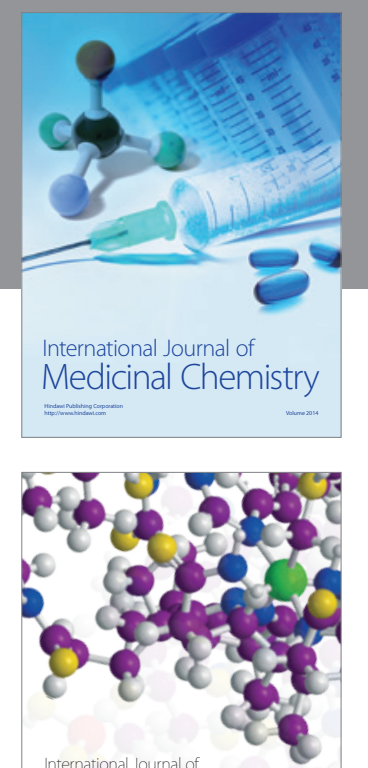

\section{Carbohydrate} Chemistry

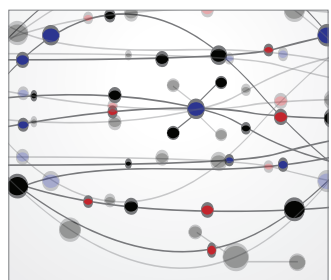

The Scientific World Journal
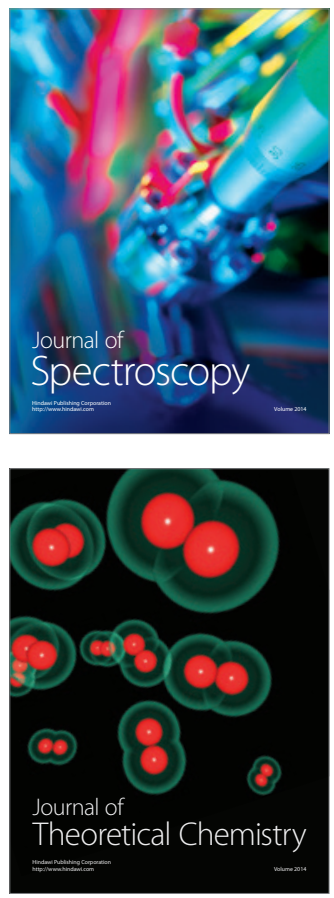
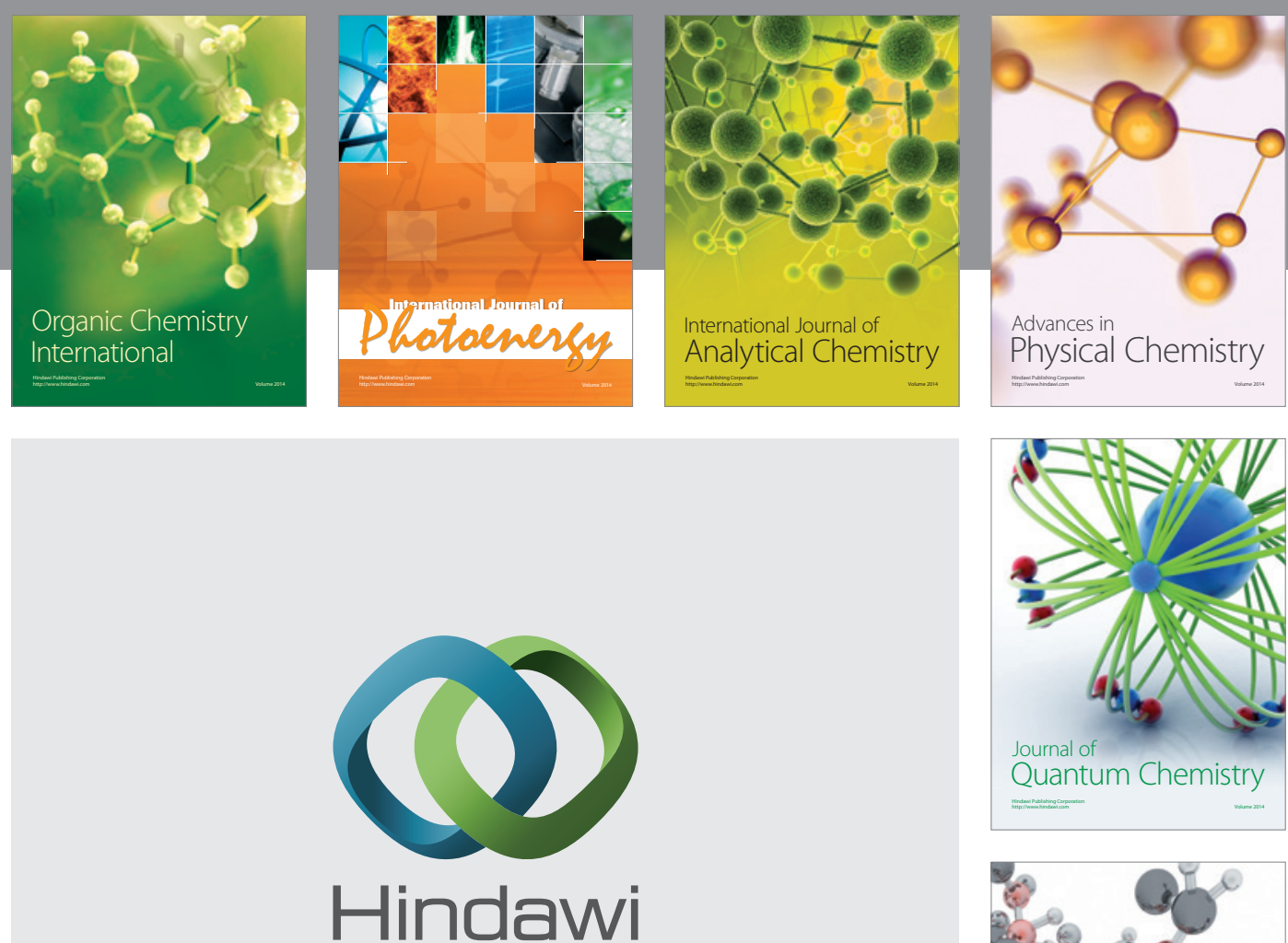

Submit your manuscripts at

http://www.hindawi.com

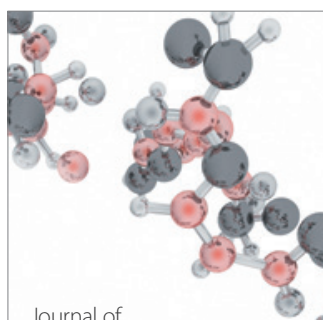

Analytical Methods

in Chemistry

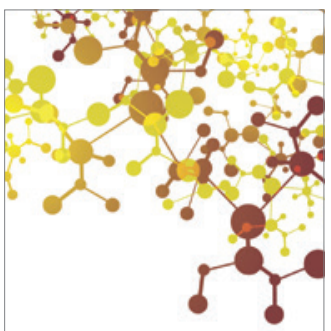

Journal of

Applied Chemistry

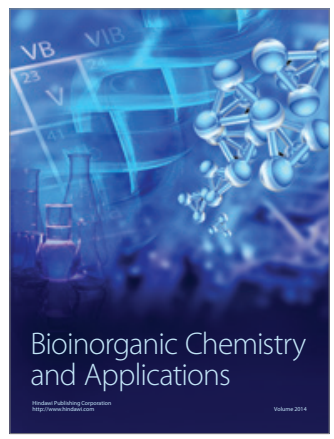

Inorganic Chemistry
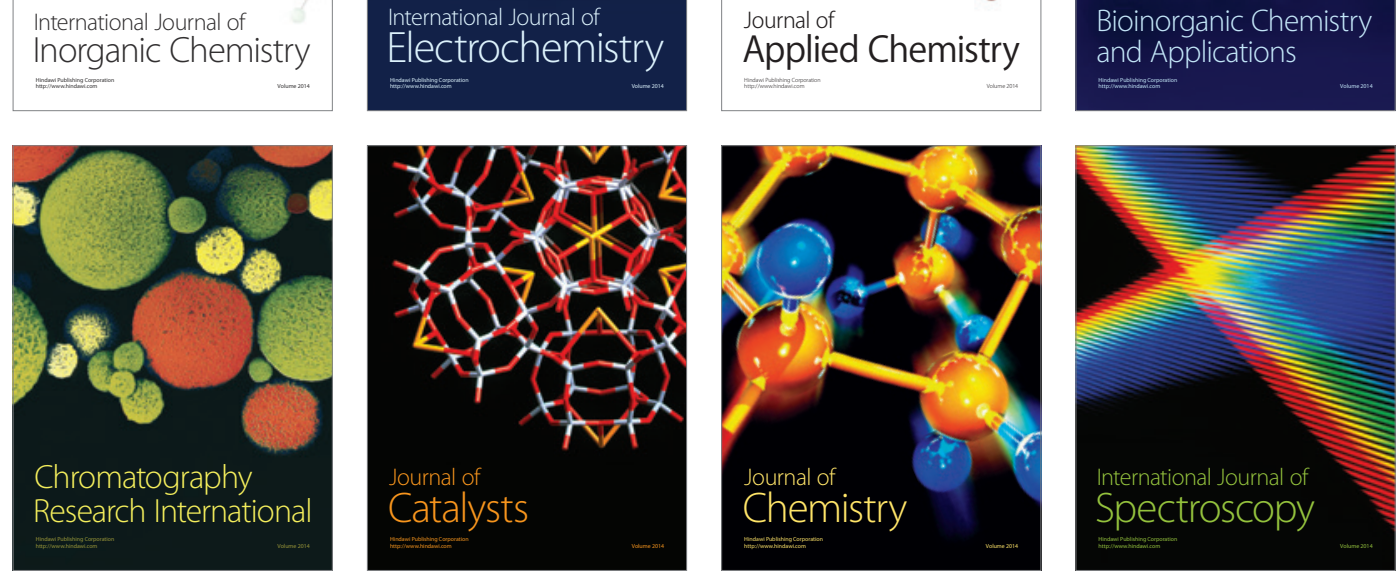